Psychology of Language and Communication 2018, Vol. 22, No. 1

DE DE GRYYTER

OPEN

DOI: $10.2478 /$ plc-2018-0001

IRINA OVCHINNIKOVA

Sechenov Moscow State Medical University, Moscow, Russia;

Perm State University, Perm, Russia

\title{
EFFECT OF THE CONTENT COMPLEXITY ON HESITATIONS IN ADOLESCENTS'NARRATIVES
}

\begin{abstract}
The paper presents analysis of the hesitations in adolescents' narratives. The speech disfluencies in the adolescents differ from those of the adults by frequency of self-corrections and pauses of hesitation. The adolescents rarely turn to repair their narratives but often interrupt the speech flow by pauses while telling a story stimulated by a wordless book. The lack of self-corrections reflects the specific problems with self-control and self-regulation due to immaturity of the executive function. Narrating about a complex multi-propositional event, the adolescents often experienced hesitation that provoked more self-repairs and hesitation pauses compared to the telling the story about a simple event. The description of the relatively simple content was more complicated syntactically than that of the multi-propositional event. Meanwhile, the content complexity significantly influences frequency of the silent hesitation pauses.
\end{abstract}

Key words: adolescents, narratives, hesitations, pause, event complexity

\section{Introduction: Goals and expectations}

This research aims to gain a better understanding of hesitations in adolescents' narratives about simple and complex events. The objectives of the research are:

1. To describe the types of hesitations in adolescents' narratives;

2. To analyze the functions of hesitations in the narratives;

3. To verify the effect of the content complexity on hesitations.

Address for correspondence: Irina Ovchinnikova, Moscow Sechenov University, 8-2, Trubetskaya St., 119991 Moscow, Russian Federation. E-mail: ira.ovchi@gmail.com 
The theoretical background of the analysis of hesitations in the process of telling a story includes a prosodic description of the hesitation and a definition of the narrative complexity.

The narrative presupposes the structuring of the event and implementation of the genre structure. Representing a genre and a text type, even a basic one, the narrative allows multiple propositions to be connected, expressing complex relations of characters and their intentions. While generating and telling a story, a narrator needs to arrange actions according to characters' goals in order to lead the narrative line to its natural conclusion. Therefore, the narrator keeps in mind the macrostructure of the story and the microstructures of its episodes at the same time; the microstructures are often complicated, involving different actors which interfere with a protagonist in his/her attempts to achieve the main goal. Even preschool children tend to create different ways of interpreting the main action and the story characters' interplay (Bokus, 2004). However, narration requires developed linguistic competence to verbalize a script. Thus, the narrative represents a complicated intellective and communicative task; the complexity of the task appears in the form of hesitations.

The verbalization of a complex script with several episodes provokes hesitations and pauses to select a word and to program a syntactic structure for the microstructure, and to clarify the value of each episode in the macrostructure (Goldman-Eisler, 1961; Scontras, Badecker, Shank, Lim, \& Fedorenko, 2015). The hesitations are manifested in self-corrections (manifestations of the monitoring processes), disfluencies (as lengthenings and word fillers), and pausing. Pauses of hesitation presuppose interruption of the speech flow that is obvious for a listener, who perceives the interruption as a segment filled with non-verbal vocalizations or a silent segment. The numerous hesitations and pausing reflect a mental disorder; nevertheless, the hesitation is regarded as a typical trait of spontaneous narratives (Levelt, 1983).

The hesitations occur in children's narratives more often than in adults' stories (Redford, 2013). Redford presumed that the quantitative difference in child and adult pausing and disfluencies are caused by the development of linguistic competence rather than by cognitive resources. However, the hesitations do not decrease gradually in the process of language acquisition. The difficulties associated with insufficiency of the linguistic competence and the developing brain appear in children's narratives. Adolescents, with linguistic competence developed close to the level of an adult (for a review, see Berman, 2004), show less disfluencies than adult storytellers (Kibrik \& Podlesskaya, 2017, p. 69). Adolescents probably experience uncertainty less often than adults due to immaturity of the executive function, which causes insufficiency of self-control and self-regulation in language performance. Thus, the hesitations in narratives reveal difficulties in language performance associated with linguistic competence, cognitive resources and maturity of the executive function, and various features of the communication. The communication 
features represent objective factors that influence the performance of all narrators; the complexity of the script and content appears to be an objective communicative feature. Thus, the content complexity induces hesitations in the narrators regardless of their linguistic competence and cognitive resources while they spontaneously tell a story.

The complexity of the syntactic construction, which often reflects the complexity of the proposition or multi-propositional semantic content, provokes hesitations and pausing even in adults (Scontras et al., 2015). The influence of the topic and motivation on the process of solving a complicated problem by adolescents is discussed in Nippold et al. (2015). Thus, hesitations and other speech parameters vary under the impact of the linguistic and cognitive complexity in children, teenagers, and adults. The effect of the complexity on programming complex syntactic structures is obvious thanks to the studies mentioned above. However, a narrator regularly verbalizes the complex content in simple syntactic structures. In this verbalization, the cognitive complexity is represented separately from the syntax complexity. To clarify the specific impact of the complexity of the event on the adolescents' narratives, we need to compare the disfluencies in the narrative fragments describing events of different complexity levels generated by the same narrator.

The hypothesis includes three presuppositions:

1. Hesitations occur in adolescents' narratives less frequently than in adults' monologues. The low frequency of hesitations is determined by the lack of monitoring and self-regulation in adolescence.

2. In adolescents, differences in the functioning of silent and filled hesitation pauses concern monitoring of the pronounced segment vs. lemme/lexical choice and production difficulty.

3. The narrative of a complex multi-propositional episode provokes more hesitations compared to a simple episode.

The hesitations and pausing in the process of generating a complex message with multiple propositions are required to combine microstructure and macrostructure processing, lexical selection, monitoring, and self-correction. The complicated propositional structure of an event/episode in spontaneous narrating increases the probability of hesitation and pausing caused by cognitive and linguistic reasons.

\section{Theoretical background}

\section{Ambiguity of hesitation definition and problems of data comparison}

Analysis of the hesitation phenomena allows for clarification of difficulties in speech generating and self-monitoring. Nonetheless, even the definition and classification of hesitations emphasize differences in approaches and disagreement in data analysis. The most detailed classification includes 80 variants of hesitations 
(Schneider, 2016). On the one hand, researchers often prefer to exclude repetitions and self-corrections (self-repairs and false starts) from the list of hesitations. The exclusion depends on the approach and objectives: Self-repairs and false starts reveal a problem and its solution, while pauses, lengthenings, and word fillers are not so transparent (Schneider, 2016, p. 67). In this research, hesitation as a category contains pauses and self-corrections according to the goal of describing hesitations in the spontaneous narratives of adolescents and intention to discuss the functions of hesitations.

On the other hand, in the classification of disfluencies, the silent and filled pauses belong to different clusters; the silent inter-clause hesitation pauses are sometimes considered as an ambiguous case beyond the hesitation phenomena (Lickley, 2015; Schneider, 2016). The hesitation belongs to performance, so, according to Ferreira (1993), there are no clues to recognize the inter-clause silent hesitation even by the duration of the inter-clause silent pause. Nevertheless, the prolonged silent pause on the clause boundary presupposes hesitation (Skehan, 2014, p. 19) and could be recognized by a listener as an interruption in the speech flow for planning a new segment to match the requirements of the current speech act. Therefore, we include the prolonged inter-clause silent pauses in the list of hesitation indicators that regularly appear in the narratives.

Inconsistency impedes data comparison for different languages. In English and Swedish, the analysis of disfluencies includes self-repairs, false starts, immediate repetitions, and filled pauses. According to the approach described above, hesitations occur in English at an average rate of 6 per 100 words (Lickley, 2015). In Russian linguistics, filled hesitation pauses are considered within pausing apart from other types of hesitation and repairs. In Russian spoken discourse, self-corrections appear with overall rates of 1.8-2.9 instances per 100 words (Podlesskaya, 2015, p. 76), while filled hesitation pauses were found approximately 6 times per 100 words (1,9 times per 100 syllables; Kibrik \& Podlesskaya, 2017). Thus, disregarding inconsistency, the rhythm of self-interrupting in the spontaneous speech appears to be alike; the comparison of the hesitation parameters is acceptable.

\section{Different functions of silent and filled hesitation pauses}

On the one hand, silent hesitation pauses are considered as a typical pause expressing hesitation in spontaneous speech. On the other hand, a silent pause is often described as an interruption of speech flow that does not belong to the hesitation phenomena. Therefore, silent hesitation pauses need to be recognized and detected among all cases of speech interruptions.

Since hesitation pauses belong to the performance, a listener needs to recognize the pauses (Ferreira, 1993); therefore, breathtaking pauses were not evaluated as hesitations. Silent hesitations are located within a clause and at clause boundaries that depend upon a narrator's individual strategy (Ventsov, Slepokurova, \& Snyuguina, 2011, p. 30). Pausing before/after a coordinate/ 
subordinate conjunction in a compound/complex sentence represents a boundary pause, while pausing between a complement and its attribute is considered as a typical hesitation pause (Hawkins, 1971). A boundary pause shows hesitation in the case of its extra-length or non-verbal vocalizations (Hawkins, 1971). In Russian, the normal duration of the clause boundary pause is limited to $0.60-0.80 \mathrm{~s}$ (Potapova \& Blokhina, 1986). Hesitation pauses on clause boundaries exceed these limits. Native Russian speakers perceive and estimate pausing longer than $0.810 \mathrm{~s}$ as a prolonged pause and a potential indication of hesitation (Potapova \& Blokhina, 1986).

The distinction between filled and silent pauses, disregarding their location within or beyond the clause, deals with several parameters of the utterance content:

1. Prolonged filled pauses seem to be the most robust correlates of production difficulty. Pausing before a conjunction facilitates comprehension of the complex clauses, as it signals the termination of a predictable model or a speech chunk (Laurinavichute \& Fedorova, 2010), especially for syntactically complex structures (Scontras et al., 2015).

2. Filled pauses before less frequent or less predictable (in the current context) words were found in Russian adults speakers (Laurinavichute \& Fedorova, 2010). Thus, filled pauses also predict difficulty in lexical selection when it does not fit the lexeme distribution in the context.

3. The distinction between filled and silent pauses reflects the contrast of the emotional attitude and cognitive activity, as Goldman-Eisler (1961, p. 25) showed by evaluating the content of cartoon descriptions. The number of short filled pauses did not exceed in accordance with the complexity of abstract content in the evaluation part, but accordingly with the complexity of the visual support (Goldman-Eisler, 1961).

4. The hesitation revealed by silent pauses is associated with the necessity to monitor the expression of the narrative line in the left context.

\section{Interpretation of the narrative complexity}

The complexity phenomenon is heterogeneous. One of the ways to measure message complexity is connected with the measurement of intellectual neurological activity during text processing (Newmeyer \& Preston, 2014): This approach could be implemented through analysis of narrative chunks corresponding to episodes with different numbers of propositions. The propositional structure reflects the structuring of an event or a sub-event and mental representation of the knowledge and texts content (Zwaan, 2016). Thus, a description of a multi-propositional episode in the narrative costs intellectual resources to clarify interconnections among propositions and to arrange results in syntactic constructions. The multi-propositional content does not obligatorily stimulate 
the generation of a complex syntax structure in the narrative since a narrator could prefer to describe the propositions in different clauses by identifying their interconnections lexically or prosodically. The prosodic segmentation of the speech flow does not match the boundaries of the syntactic constructions and clauses (Ferreira, 1993); therefore, the complexity of the content and speech act itself is revealed in hesitations regardless of the syntax of the utterance (Ventsov, Slepokurova, \& Snyuguina, 2011). Since the task is complicated, the speech flow could be interrupted even within a clause. Thus, a description of a multi-propositional episode in the narrative contains complex content without reference to the syntax complexity of the description.

\section{Material and methods}

\section{Description of the material}

The Frog Story, a wordless book with 24 images (Mayer, 1969), is well known thanks to cross-cultural research on the relating of events by young children (Berman \& Slobin, 2013). For the research of the content complexity, descriptions of Images 12 and 21 were selected from the adolescent's narratives. To be precise, the description of the 12th image was analyzed by Slobin (2006) to clarify tools expressing the diversity in the verb usage in different languages. The episode is considered as complicated and compound, and that is shown through the goal-directed analysis.

In the goal-directed version of the narrative analysis (Stein \& Glenn, 1975), the 12th image is correlated with Event \#28 where the boy achieved a sub-goal by investigating if anything is in the tree, while the 2 nd image is connected to Event \#60 when the boy with the dog finally found his escaped frog (Lynch \& Broek, 2007, p. 324).

Event \#28 accommodates a combination of different simultaneous actions performed by four agents: an owl frightened the boy, the boy fell from a tree, his dog ran away from wasps, and the wasps hunted the dog. The event contains cause-effect relationships (the boy fell because the owl frightened him) and evaluation of two misfortunes that happened to the protagonist and his collaborator on their way to achieve the main goal.

In the simple episode of Event \#60, the boy and his dog found something behind a log. They experienced the process (to watch) and the state (to lay) before realizing that they already reached the termination stage of their adventure. The protagonist and his collaborator belong to the same proposition. The simple episode is associated with the achievement of the main goal of the narrative. Therefore, distinctions between the events include:

1. The number of the agents: four (the owl, the boy, the dog, the wasps) vs. one agent with the co-agent (the boy with the dog); 
2. The number of the propositions: four (to frighten, to fall, to run, to hunt) vs. two (to watch, to lay);

3. The class of the events: the accomplishments and achievements vs. the process and state as the initial phase of the achievement; ${ }^{1}$

4. The role in the narrative line: reaching a sub-goal vs. achieving the main goal.

The fragments associated with Images 12 and 21 of the Frog, Where Are You? stories generated by Russian teenagers were extracted from the records of narratives to examine the significant dissimilarities between hesitations in describing complex and simple episodes. The syntax complexity of the fragments was examined on the basis of usage of subordinate conjunctions, gerund and participle constructions, and passive clauses.

The whole narratives were analyzed qualitatively and quantitatively.

\section{Participants}

Thirty-eight adolescents (aged 14-15 years) participated in the present study. All of them at the moment of the interview studied at school in the 8th grade; the respondents belonged to middle-class families from the city of Perm (Western Ural, Russia). The students studied English at school from the 2nd grade. They were familiar with cross-cultural communication thanks to foreign visitors to their school; some of them participated in different cultural and educational programs abroad.

\section{Procedure}

The study was conducted on the basis of Frog Story wordless book (Mayer, 1969). Interviewers worked with the respondents individually in the friendly environment at school; the interviews were conducted face to face by two students in the 5th year of the Theoretical and Applied Linguistics Section within the Philological Faculty at Perm State University. The adolescents viewed the images in the wordless book before getting started with storytelling. The narratives were recorded in a non-shared attention modus, the narrators followed the images while telling their stories. The microphone was at a fixed distance from the speaker, and the recording in digital format was carried out with a sampling frequency of $22 \mathrm{kHz}, 16$ bit sample resolution. All records were examined using Adobe Audition 3.0.

\section{Research design}

The main unit of the current analysis is the hesitation represented by disfluencies (non-verbal vocalizations, lengthenings), false starts, specific pauses, and on-line self-repairs. These manifestations of the hesitation were annotated

\footnotetext{
${ }_{1}$ The class of the events, which represent sub-events of the narrative field, refers to the event categories in the Croft's (2012) classification.
} 
and segmented manually using Adobe Audition 3.0 by one of the interviewers and an expert phonetician. According to the standard for a records description, the following parameters were summarized:

- Length of the narratives in words;

- Duration of the narratives;

- Number and duration of the different hesitation pauses. The threshold for the minimum inter-clause silent hesitation pause was set at $81 \mathrm{~ms}$;

- Number of the self-corrections after silent and filled hesitation pauses;

- Length in words and syntax complexity in the descriptions of the complex multi-propositional and simple episodes.

The recognition of pauses and their duration measurement match the standard procedures as in a study by Kibrik and Podlesskaya (2017).

It is important to note that three of the narrators completely omitted a description of the complex episode; 10 of them simplified it and mentioned only one proposition, avoiding discussion of the narrative field; five adolescents neglected a description of the simple episode. From 38 adolescents' narratives, 18 were chosen for statistical analysis by ANOVA (SPSS Statistics 17.0) to verify trends in the balanced sample, which are relevant in the totality. The chosen records represent a balanced sample meeting the requirements for applying ANOVA to verify the significance of the impact of the factor "multi-propositional complexity", disregarding gender differences in speech behavior. The balanced sample contains narratives produced by nine boys and nine girls; all of the 18 respondents have some experience in cross-cultural communication and generated descriptions of the complex and simple episodes.

The total duration of the 18 narratives records reached $74.3 \mathrm{~min}$; narrative duration varied within $1.03-5.09 \mathrm{~min}$.

\section{Results}

\section{General analysis of the hesitation pauses}

The number and duration of hesitation pauses in the narratives are represented in Table 1.

The duration of the 18 narratives is $4,484.9 \mathrm{~s}$; the material contains 4,150 words (without non-verbal vocalizations and filler words). The records include 737 hesitation pauses, lasting $642.75 \mathrm{~s}$. Hesitation pauses occurred at an average rate of 17.76 per 100 words. All hesitation pauses in the narratives cover $14.3 \%$ of the total speech duration. A typical hesitation pause of an adolescent's narrative appears to be a filled intra-clause pause; this type of pauses covers almost $40 \%$ of the hesitations and one-third of the hesitation pauses total duration. The average inter-clause filled pause lasted three times shorter than the silent one. Non-verbal vocalizations within a clause during a moment of uncertainty are 
probably caused by involuntary activation of the articulatory mechanism when a narrator intuitively understands that the time limit for silence is exhausted. The inter-clause pause lasts longer because it absorbs a regular boundary pause; the filled boundary pause includes the non-verbal vocalization duration.

Table 1. Types of the Hesitation Pauses in the Adolescents' Narratives

\begin{tabular}{lllllll}
\hline \multicolumn{1}{c}{ Pause type } & \multicolumn{2}{c}{ Silent pauses } & \multicolumn{2}{c}{ Filled pauses } & \multicolumn{2}{c}{ Total } \\
\hline Pauses per 100 words in total & \multicolumn{2}{c}{7.83} & \multicolumn{2}{c}{9.93} & \multicolumn{2}{c}{17.76} \\
\hline \multicolumn{1}{c}{ Pause category } & $\begin{array}{l}\text { Inter- } \\
\text { clause }\end{array}$ & $\begin{array}{l}\text { Intra- } \\
\text { clause }\end{array}$ & $\begin{array}{l}\text { Inter- } \\
\text { clause }\end{array}$ & $\begin{array}{l}\text { Intra- } \\
\text { clause }\end{array}$ & $\begin{array}{l}\text { Inter- } \\
\text { clause }\end{array}$ & $\begin{array}{l}\text { Intra- } \\
\text { clause }\end{array}$ \\
\hline Number of pauses $_{\text {Duration }^{\mathrm{a}}}$ & 211 & 114 & 124 & 288 & 335 & 392 \\
Average pause duration $^{\mathrm{a}}$ & 171.73 & 28.02 & 229.12 & 213.88 & 400.85 & 241.90 \\
Pauses in the category per $_{100 \text { words }}$ & 0.81 & 0.25 & 1.85 & 0.74 & 1.197 & 0.59 \\
\hline
\end{tabular}

aPause duration in seconds.

However, the ANOVA did not verify the significance of the pause number and duration differences in total. The number and duration of the filled and silent pauses fluctuated within the groups due to individual variations. The number and duration of silent/filled pauses within a clause did not deviate markedly from the same parameters of pausing on the clause boundaries. Gender did not influence the hesitations significantly, according to ANOVA (Table 5). In the narratives, the variation of the hesitation pauses within the same gender was more significant than between the two genders.

\section{Types of hesitations in the adolescents' narratives}

The following hesitation pauses occurred in the adolescents' narratives:

1. Silent prolonged boundary pauses expressing hesitation:

(1) Ааа... его собака тоже... ну... вспрыгнула на подоконник и... посмотрела в окно и упала... (4.52 s)

Aaand... his dog also... well... jumped onto the windowsill and... looked out the window and fell down... (4.52 s)

2. Filled pauses on clause boundaries manifesting hesitation:

(2) (2.17 s) Мм... потом он обнаружил что а... окно открыто и... подумал что ... что... лягушка могла уйти ... выпрыгнуть через окно

(2.17 s) Hmm... then he discovered that w... window was opened and ... he thought that ... that ... the frog could leave... jump out of the window 
3. Silent hesitation intra-clause pauses without repetitions or on-line repairs:

(3) Мм... (1.40 s) оттуда высскочила... (0.90 s) сова

Hmm... (1.40 s) from there jumped...(0.90 s) the owl

4. Silent hesitation intra-clause pauses preceding repetitions, as 'что... чтоо... (that... that...)' in (2) or on-line repairs as 'лягушка могла уйти... выпрыгнуть через окно (the frog could leave... jump out of the window)' in (2)

5. Filled hesitation intra-clause pauses without repetitions/on-line repairs, as ones with a non-verbal vocalization 'ээ...(uh-uh)' in (4):

(4) Лягушка этого мальчика ээ... выпрыгнула из... своей посудины ... A frog of this boy wh-uh... jumped out of ... her jar...

6. Filled hesitation intra-clause pauses preceding repetitions or on-line repairs:

(5) (1.39 s) Ээ... у большого оврага мальчик ээ... мальчик упал...

(1.39 s) Uh-uh... at a large ravine the boy uh-uh... the boy fell down

7. False starts:

(6) Ээ... он... настала ночь ээ...

Uh-uh... he... the night came $u h-u h .$.

8. Lengthenings (prolongation of a word segment), as 'Aaa... (And)' in (1).

The hesitation filler words - as $\mathrm{ky}$ (well) in (1) - occurred five times in all the narratives and did not significantly affect the distribution of hesitations. Off-line self-repairs did not occur in these narratives; the rareness (or even absence) of the off-line self-repairs is considered typical of spontaneous speech (Levelt, 1983).

\section{Self-corrections in the adolescents' narratives}

The typical filled pause rarely precedes self-corrections; the pausing reflects programming of the utterance (the data for different self-corrections are presented in Table 2.).

Self-corrections follow silent hesitation pauses. The silent pause provides time for monitoring an articulated speech segment and verifying its relevance to the semantic program of the utterance.

In almost half of the self-repairs, a narrator interrupted the speech flow to repair an inappropriate word immediately. Levelt (1983, p. 63) showed the difference between self-repairing an error and an inappropriate word: An error was usually self-repaired within reparandum, while an inappropriate word was completed before the repair. Nonetheless, the adolescents turned to 
repair even inappropriate words immediately; self-repairs within reparandum appeared in half of the cases (Table 2).

Table 2. Types of the Self-Corrections in the Adolescents' Narratives, Including Descriptions of Images 12 and 21

\begin{tabular}{lcccccccc}
\hline & \multicolumn{3}{c}{$\begin{array}{c}\text { Correction after silent hesitation } \\
\text { pauses }\end{array}$} & \multicolumn{3}{c}{$\begin{array}{c}\text { Correction after filled hesitation } \\
\text { pauses }\end{array}$} \\
\cline { 2 - 10 } $\begin{array}{l}\text { Type of } \\
\text { self- } \\
\text { correction }\end{array}$ & $\begin{array}{l}\text { Repeti- } \\
\text { tion }\end{array}$ & $\begin{array}{l}\text { On-line } \\
\text { repair } \\
\text { (within } \\
\text { reparan- } \\
\text { dum) }\end{array}$ & $\begin{array}{l}\text { False } \\
\text { start }\end{array}$ & $\begin{array}{l}\text { Leng- } \\
\text { the- } \\
\text { ning }\end{array}$ & $\begin{array}{l}\text { Repeti- } \\
\text { tion }\end{array}$ & $\begin{array}{l}\text { On-line } \\
\text { repair } \\
\text { (within } \\
\text { reparan- } \\
\text { dum) }\end{array}$ & $\begin{array}{l}\text { False } \\
\text { start }\end{array}$ & $\begin{array}{l}\text { Leng- } \\
\text { the- } \\
\text { ning }\end{array}$ \\
\hline $\begin{array}{l}\text { Image 12 } \\
\text { Image 21 }\end{array}$ & 1 & $5(3)$ & 0 & 4 & 0 & $1(1)$ & 0 & 0 \\
$\begin{array}{l}\text { Total in the } \\
\text { narratives }\end{array}$ & 7 & 0 & 0 & 3 & 0 & 1 & 0 & 0 \\
\hline
\end{tabular}

\section{Difference between narrations about complex and simple events}

The fragments of narratives corresponding to Images 12 and 21 cover $10.75 \%$ and $5.71 \%$ of the total number of words, respectively. The descriptions of the complex multi-propositional episode contained 446 words, approximately 25 words per description. The number of sentences in the fragment varied from one to four. Meanwhile, the simple episode was described by the teenagers in 230 words, close to 13 words per description, and contained one or two sentences. The fragment for the 21 st image was more complicated syntactically than that for the 12th image with four propositions (Table 3).

Table 3. Syntax Complexity of the Adolescents' Descriptions of Images 12 and 21

\begin{tabular}{lccc}
\hline Syntactic structure & $\begin{array}{c}\text { Subordinate clause } \\
\text { (per 100 words) }\end{array}$ & $\begin{array}{c}\text { Passive construction } \\
\text { (per 100 words) }\end{array}$ & $\begin{array}{c}\text { Gerund } \\
\text { and participle } \\
\text { constructions } \\
\text { (per 100 words) }\end{array}$ \\
\hline Image 12 & $15(3.36)$ & $1(0.22)$ & $1(0.22)$ \\
Image 21 & $11(4.64)$ & $2(0.84)$ & $4(1.69)$ \\
\hline
\end{tabular}

To describe the state-event of Image 21, adolescents employed gerund and participle constructions.

The number and duration of hesitation pauses in the descriptions are presented in Table 4. The prevalence of the hesitations in the fragment with complex content depended on the length of the description; the probability of disfluencies was higher for a vocabulary-rich speech segment. Self-corrections were more frequent in the fragments with complex content. Self-repair represents 
the most frequent self-correction. The descriptions of Image 12 contain six times as many repairs as the descriptions of Image 21 (data in Table 2).

Table 4. Types of Hesitation Pauses in the Adolescents' Descriptions of Images 12 and 21

\begin{tabular}{|c|c|c|c|c|c|c|}
\hline Pause type & Silent & gauses & Filled & pauses & & tal \\
\hline Pauses per image & 12 & 21 & 12 & 21 & 12 & 21 \\
\hline Number of pauses & 30 & 9 & 29 & 7 & 59 & 16 \\
\hline Duration $^{\mathrm{a}}$ & 17.90 & 7.33 & 6.28 & 4.29 & 24.18 & 11.62 \\
\hline Average pause duration ${ }^{\mathrm{a}}$ & 0.62 & 0.81 & 0.21 & 0.61 & 0.41 & 0.69 \\
\hline Pauses per image per 100 words & 6.72 & 3.91 & 6.50 & 3.04 & 13.22 & 6.94 \\
\hline
\end{tabular}

${ }^{\text {a }}$ Pause duration in seconds.

The length in words and duration of the narrative fragments with four actors was almost twice higher than those for the fragments with one actor and his collaborator. However, the number of pauses in the complex multi-propositional narrative fragments for the 12th image was almost four times higher than that of the 21st image descriptions (59 vs. 16). The frequency of hesitation pauses in the "complicated fragment" was also higher than in the simple one (13.22 vs. 6.95 per 100 words). The statistical significance of the difference in the hesitation pauses was verified by ANOVA (SPSS Statistics 17.0).

Table 5. The Significance of Differences in Hesitation Pauses in the Descriptions

\begin{tabular}{lccccc}
\hline Factor & $\boldsymbol{F}$ critical & $\begin{array}{c}\boldsymbol{F} \text { for } \\
\text { filled pauses }\end{array}$ & $\begin{array}{c}\boldsymbol{F} \text { for } \\
\text { silent pauses }\end{array}$ & $\begin{array}{c}\boldsymbol{F} \text { for } \\
\text { filled pauses } \\
\text { duration }\end{array}$ & $\begin{array}{c}\boldsymbol{F} \text { for } \\
\text { silent pauses } \\
\text { duration }\end{array}$ \\
\hline $\begin{array}{l}\text { Content } \\
\text { complexity }\end{array}$ & $F(1,16)=4.49$ & $3.645^{*}$ & $4.676^{* *}$ & 2.815 & 0.477 \\
$\begin{array}{l}\text { Gender } \\
* p<10, * * p<05\end{array}$ & $F(1,7)=5.59$ & 0.312 & 0.049 & 0.001 & 0.002 \\
\hline
\end{tabular}

The ANOVA results for the factor Content complexity (Table 5) show that the difference in the silent hesitation pause numbers between two fragments was significant: $F(1,16)=4.68$, higher than $F$ critical $=4.49$. Thus, in the descriptions of the 12th image, the adolescents made silent pauses more often than it was theoretically expected. The narrators also paused filling the constrained silence with non-verbal vocalizations more frequently while describing the complex event; however, the difference for the filled pauses was significant only for $p<0.10$, where $F$ critical $=3.048$. Therefore, in adolescence, telling a complicated story with multiple propositions connected to sub-goals of the narrative field brings multiple hesitation pauses to the narrative regardless of its syntactic complexity. 


\section{Discussion}

\section{Different functions of hesitations and pausing}

In this study, the types of hesitations are considered according to the studies by Rose (2013) and Lickley (2015). All variety of the hesitations appeared in the adolescent's narratives, but narrators paused more frequently than they made a self-correction in their speech flow. Self-corrections express monitoring of the preceding segment during its vocalization on the background of the microstructure of the clause, dealing with:

(a) a grammar indicator, as in the following example:

(7) за собакой погналась... погнался рой пчел

(a swarm of bees chased (PST.SG.F)... chased (PST.SG.M) a dog)

(b) a lexical choice (as in (2)).

Meanwhile, the pausing also contains monitoring of the macrostructure and the narrative line as well. After describing Event \#28, a girl continued the story, mentioning the main goal:

(8) дальше они пошли...видимо к берегу ...ээ... реки и стали искать здесь лягуику

then they went ... apparently to the bank... uh-uh... of the river and began looking for the frog here

By appealing to the macrostructure and marking the end of the narrative field description, the adolescent refreshed the phase of the narrative line. Therefore, the most important distinction between functions of the on-line self-correction and the pausing deals with a scale for speech goals: the current utterance coherence vs. the whole narrative cohesion.

\section{Frequency of self-corrections in comparison with adult speakers}

In spoken Russian, as it has been mentioned above, self-corrections appear with overall rates of 1.8-2.9 instances per 100 words (Podlesskaya, 2015, p. 76); in the narratives of this study, self-corrections appear in 1.59 instances per 100 words. Evidently, the lower frequency of the self-corrections is determined by the difference between conversation and narration. Specific features of the language behavior in adolescence also affect the frequency of the self-repairs. The deficiency in self-control and self-regulation affects the process of speech monitoring. This lack is a reason for using an inappropriate and even erroneous word or neglecting the necessity to repair a speech segment. For example, the narrators made mistakes naming animals: the little frog was referred as a hoptoad; the boy found a hamster/ a rat /a skunk in a hole, etc. Besides pronouncing wrong names, the adolescents misused language styles and switched to the colloquial speech. The narrators missed chances to correct 
inappropriate words or a colloquialism at least twice per narrative. Therefore, cases for potential self-corrections are close to those in adults. The adolescents produced disfluencies with lower frequency, but pausing for hesitation more often than adults. The lack of self-repairs in adolescence is caused by the immaturity of the executive function and inhibitory control (Brocki \& Bohlin, 2004).

\section{Frequency and duration of the hesitation pauses in adolescents' narratives with or without visual support}

The temporal and segmental characteristics of the adolescents' narratives match the parameters of the Russian spontaneous speech defined in Bondarko, Volskaya, Tananaiko, and Vasilieva (2003) or in Potapov and Potapova (2017). The results of this analysis are consistent with other studies of monologues (Podlesskaya, 2015) and hesitations (Lickley, 2015) in general. However, the frequency of self-corrections and hesitation pauses in adolescence differs from adults. In spontaneous speech, the adolescents paused experiencing hesitation at an average rate of 17.76 per 100 words, almost 3 times as often as adults do (for a review, see: Lickley, 2015). Russian night dream storytellers of the same age also interrupted their narratives less often than our teenagers (Kibrik \& Podlesskaya, 2017). The dissimilarity could be caused by the task to tell the story based on the visual support. The narrators probably interrupted the speech flow to verify the overlapping between verbal description and visual support.

Hesitation pauses in the narratives cover $14.3 \%$ of the total speech duration, while according to Kibrik and Podlesskaya (2017, p. 69) the duration of pauses fits $25 \%$ of the total duration of night dream stories. So our narrators interrupted their speech more often, but the interruptions were short in comparison with the night dream storytellers. First of all, in the study by Kibrik and Podlesskaya, the pause duration includes all pausing, even short boundary pauses without hesitation. Secondly, the numerous short pauses of hesitation in the Frog Stories are determined by the visual support of the wordless book. Comparing narratives and conversation in adolescents, researches argue that the narrative based on the wordless support material is a better prompt for employing long complex sentences than a conversation task (Nippold et al., 2014, pp. 880-881). Producing long complex sentences generates opportunities for hesitation; this is the first explanation for the numerous hesitations. The illustration provides the variants for selecting an agent and potential arguments for the proposition. Thus, a narrator often interrupts his or her speech to follow the images and spends less time on hesitation thanks to the visual support; this is the second point to explain the short but numerous hesitations. 


\section{Difference in the functioning of silent and filled pauses in adolescents' narratives}

As it has been mentioned above, filled and silent hesitation pauses are considered different and function variously.

Generally, the distinctions described above are relevant to our records. The filled pauses in our records regularly appeared within a clause as an indicator of selecting an appropriate lexeme. The appropriate lexeme often belongs to the low frequency category. For example, the word дупло (a hollow) appears in the Russian Corpora of Spoken Language with the relevant grammatical endings in 21 contexts $^{2}$. All of the narrators paused and filled the pause with non-verbal vocalization at least once per narrative before pronouncing the lexeme. The intra-clause filled pauses, the most frequent hesitations in our records, indicated the difficulties in lexeme or even lemma selection for describing the image. Thus, the filled pause marks a moment of perplexity in speech production caused by lexeme selection or complex syntactic construction programming. The intra-clause silent pauses preceded the verification of the recently pronounced speech chunk, as in (3), or its correction, as in (7).

However, the intra-clause filled pause in the adolescents' Frog Stories lasted longer than the same pauses in the night dream monologues (Kibrik \& Podlesskaya, 2017, pp. 67-68). Filled pauses are short: An average silent pause lasts longer than a filled one, and also the duration of the filled pauses in the narratives does not exceed $28 \%$ of the total pausing duration (Kibrik \& Podlesskaya, 2017, p. 69).

Probably, the intra-clause filled pause long duration represents the involuntary reaction of our adolescents' to their intuitive estimation of the time limits for an intra-clause silence; thus, the filled pause might have included a silent hesitation pause and vocalization when the narrators tried to evaluate the necessity and relevance of the rectification of the recently pronounced segment. Therefore, the filled pauses within a clause do not represent a homogeneous category; the heterogeneity of the pauses needs to be examined in the future. Meanwhile, the distinction between filled and silent pauses within the clause appears to correlate with production difficulty vs. monitoring of the pronounced speech segment and self-control of the expressed narrative line. The silent pause is more often required for verifying the narrative cohesion.

Regarding the distinction between filled pauses for reconsidering the emotional attitude and silent pauses for solving a cognitive task (Goldman-Eisler, 1961), our material confirms the feature for complex episode description. The number of filled pauses corresponds with the complexity of the visual support (cartoon; see: Goldman-Eisler, 1961).

\footnotetext{
2 The volume of the Spoken sub-corpus (http://ruscorpora.ru/search-spoken.html): 3,913 documents; 1,750,662 sentences; 12,113,491 words; the data relevant on July 23, 2017.
} 


\section{Difference in narrating about the complex multi-propositional vs. simple event}

Adolescents acquire metalinguistic strategies to facilitate performing challenging communication tasks (Berman, 2007). Thanks to the strategies, self-corrections in the adolescents' narratives appear rarely relative to the younger children and even more rarely than in adults' speech, which becomes obvious through the comparison of our data with Rose (2013) and Podlesskaya (2015). Nevertheless, the number of hesitations differs within the adolescents' narratives under the influence of the content complexity. Adolescents corrected their narratives more frequently when describing the event with four agents performing different actions, e.g., accomplishments and achievements (Event \#28, Image 21), than while referring to the simple state-event (Event \#60, Image 12).

Usually, teenagers made corrections in their narratives on-line after hesitation pauses within a clause. However, pausing without self-corrections occurs more frequently: Per 100 words, thirteen pauses occurred in the descriptions of Image 12 and almost seven in those for Image 21 . The rhythm of pausing appears to correlate roughly with the syntactic segmentation of Russian speech. An average Russian phrase contains 2.7 words (Iomdin \& Lobanov, 2009), an average sentence includes from 9.31 (Kravchenko, 2014) to 10.38 words (Katinskaya \& Sharoff, 2015). In the fragments, hesitation pauses occur after 7-8 words and after 14-15 words for the 12th and the 21 st images, respectively. A teenager experienced one hesitation during talking about the 21 st image (16 pauses per 18 descriptions); the pause matches a clause boundary or appears within a clause according to an individual strategy (Potapov \& Potapova, 2017). Meanwhile, talking about the boy falling down on the ground almost on the head of his dog running from the wasps (Image 12), teenagers kept silent or filled a pause with non-verbal vocalizations after approximately three phrases; a narrator experienced uncertainty at least three times (59 pauses per 18 descriptions), almost matching four propositions.

The type of pause (silent vs. filled) did not correlate with the pause frequency in the whole narratives, but the content complexity seems to be an important factor for the pausing during storytelling. The distinction between the silent and filled pauses in the descriptions of Images 12 and 21 was confirmed statistically: The content complexity appears to be a significant factor to provoke hesitation in adolescents. Silent pauses are responsible for cognitive problem solving during communication and narration with visual support (Goldman-Eisler, 1961). Probably, a prolonged silent pause allows reconsidering the connection of the actions with the main goal in the narrative line. The complexity is not connected with the syntax of the clauses in the descriptions, but with the difficulty of interpreting and verbalizing the interrelations of the actions in the episode and the sub-goal within the macrostructure of the narrative. 
Hesitation pausing in adolescence reveals the effect of the cognitive development and psychological/neuropsychological maturing on the language competence and performance. Therefore, the cognitive complexity is an essential factor affecting speech flow in adolescence.

\section{Conclusions}

The presuppositions of the hypotheses have been confirmed by the results of the adolescents' narratives analysis. Hesitations, excluding pausing, rarely occurred in the narratives. However, pauses of hesitation regularly interrupted the Frog Stories.

The low appearance of self-corrections in adolescents' narratives relative to the adults is caused by the immaturity of self-regulation. The adolescents compensate the lack of self-correction by numerous hesitation pauses. Therefore, the distinction of the hesitation and pausing between adolescents and adults concerns the necessity to control the narrative line and microstructure of the narrative during the speech interruption constrained by this necessity. The hesitation pauses are short, but frequent; intra-clause filled hesitation pauses are typical of adolescents due to the necessity to select appropriate words for the images. The content complexity provokes more frequent pausing for hesitation due to the necessity of arranging the speech structure according to the simultaneous actions of different agents. The disfluencies in the adolescents' narrative reveal the contradictions of this specific stage of mental development. Obviously, the adults have their specific marks for the content complexity in speech flow, such as slowing of speech and frequency of hesitation pauses. In the future, the accurate classification of filled and silent hesitation pauses will allow for a better understanding of the correlation between content complexity, syntactic complexity, and hesitation during speech production.

\section{Acknowledgements}

I would like to thank the reviewers of the manuscript for their remarks, which helped me to improve the manuscript.

\section{References}

Berman, R. A. (Ed.). (2004). Language development across childhood and adolescence (Vol. 3). Amsterdam/Philadelphia: John Benjamins Publishing.

Berman, R. A. (2007). Developing linguistic knowledge and language use across adolescence. In E. Hoff \& M. Shatz (Eds.), Blackwell handbook of language development (pp. 347-367). Chicester: John Wiley and Sons.

Berman, R. A., \& Slobin, D. I. (Eds.). (2013). Relating events in narrative: A crosslinguistic developmental study. New York, NY: Psychology Press. 
Bondarko, L. V., Volskaya, N. B., Tananaiko, S. O., \& Vasilieva, L. A. (2003). Phonetic properties of Russian spontaneous speech. In M.-J. Solé (Ed.), Proceedings of the 15th International Congress of Phonetic Sciences (pp. 2973-2976). Barcelona: ICPhS Organizing Committee.

Brocki, K. C., \& Bohlin, G. (2004). Executive functions in children aged 6 to 13: A dimensional and developmental study. Developmental Neuropsychology, 26(2), 571-593. doi:10.1207/s15326942dn2602_3

Bokus, B. (2004). Inter-mind phenomena in child narrative discourse. Pragmatics. Quarterly Publication of the International Pragmatics Association (IPrA), 14(4), 391-408. doi:10.1075/prag.14.4.01bok

Croft, W. (2012). Causal structure in verbal semantics and argument realization. Oxford: Oxford University Press.

Ferreira, F. (1993). Creation of prosody during sentence production. Psychological Review, 100(2), 233. doi:10.1037/0033-295X.100.2.233

Goldman-Eisler, F. (1961). A comparative study of two hesitation phenomena. Language and Speech, 4(1), 18-26. doi:10.1177/002383096100400102

Hawkins, P. R. (1971). The syntactic location of hesitation pauses. Language and Speech, 14(3), 277-288. doi:10.1177/002383097101400308

Iomdin, L. L., \& Lobanov, B. M. (2009). Syntactic correlates of prosodically marked elements of the sentence and their role in the tasks of-text-to-speech synthesis. Kompjuternaja Lingvistika i Intellektual'nye Texhnologii: Trudy Mezhdunarodnoj Konferentsii "Dialog 2009” [Computational Linguistics and Intellectual Technologies: Proceedings of the International Conference "Dialogue 2009”], 8(15), 136-142.

Katinskaya, A., \& Sharoff, S. (2015). Applying multi-dimensional analysis to a Russian webcorpus: Searching for evidence of genres. BSNLP 2015, 65.

Kibrik, A., \& Podlesskaya, V. (Eds.). (2017). Nightdream stories: The corpus study of Russian discourse. Moscow: Litres.

Kravtchenko, E. (2014). Predictability and syntactic production: Evidence from subject omission in Russian. Proceedings of the Cognitive Science Society, 36(36), 785-790.

Laurinavichute, A. K., \& Fedorova O. V. (2010). Effects of hesitation in speech on syntactic structure in comprehension: Evidence from Russian speakers. Kompjuternaya Lingvistika i Intellektual'nye Tekhnologii: Trudy Mezhdunarodnoj Konferentsii "Dialog 2010” [Computational Linguistics and Intellectual Technologies: Proceedings of the International Conference “Dialogue 2010”], 9(16), 279-283.

Levelt, W. J. (1983). Monitoring and self-repair in speech. Cognition, 14(1), 41-104.

Lickley, R. J. (2015). Fluency and disfluency. In M. A. Redford (Ed.), The handbook of speech production (pp. 445-474). Malden, MA: Wiley Blackell. doi:10.1002/9781118584156.ch20 
Lynch, J. S., \& van den Broek, P. (2007). Understanding the glue of narrative structure: Children's on-and off-line inferences about characters' goals. Cognitive Development, 22(3), 323-340. doi:10.1016/j.cogdev.2007.02.002. Mayer, M. (1969). Frog, where are you? New York, NY: Dial Press.

Newmeyer, F. J., \& Preston, L. B. (Eds.). (2014). Measuring grammatical complexity. Oxford: Oxford University Press.

Nippold, M. A., Frantz-Kaspar, M. W., Cramond, P. M., Kirk, C., HaywardMayhew, C., \& MacKinnon, M. (2014). Conversational and narrative speaking in adolescents: Examining the use of complex syntax. Journal of Speech, Language, and Hearing Research, 57(3), 876-886. doi:10.1044/10924388(2013/13-0097).

Nippold, M. A., Frantz-Kaspar, M. W., Cramond, P. M., Kirk, C., HaywardMayhew, C., \& MacKinnon, M. (2015). Critical thinking about fables: Examining language production and comprehension in adolescents. Journal of Speech, Language, and Hearing Research, 58(2), 325-335. doi:10.1044/2015_JSLHR-L-14-0129.

Podlesskaya, V. I. (2015). A corpus-based study of self-repairs in Russian spoken monologues. Russian Linguistics, 39(1), 63-79. doi:10.1007/s11185-0149142-1.

Potapov, V., \& Potapova, R. (2017). Jazik, reč, lichnost' [Language, speech, personality]. Moscow: Litres.

Potapova, R., \& Blochina, L. (1986). Sredstva fonetičeskogo členenija rečevogo potoka v nemetskom I russkom jazykah [Facilities for phonetic segmentation of speech flow in German and Russian]. Moscow: Linguistic University.

Rose, R. L. (2013). Crosslinguistic corpus of hesitation phenomena: A corpus for investigating first and second language speech performance. In Proceedings of the Annual Conference of the International Speech Communication Association, INTERSPEECH (pp. 992-996). Lyon: International Speech and Communication Association.

Schneider, U. (2016). Hesitation placement as evidence for chunking. In H. Behrens \& S. Pfänder (Eds.), Experience counts: Frequency effects in language (pp. 61-90). Berlin: De Gruyter.

Scontras, G., Badecker, W., Shank, L., Lim, E., \& Fedorenko, E. (2015). Syntactic complexity effects in sentence production. Cognitive Science, 3(39), 559-583. doi:10.1111/cogs.12168.

Skehan, P. (Ed.). (2014). Processing perspectives on task performance (Vol. 5). Amsterdam/Philadelphia: John Benjamins Publishing Company.

Slobin, D. I. (2006). What makes manner of motion silent? Explorations in linguistic typology, discourse, and cognition. In M. Hickmann \& S. Robert (Eds.), Typological studies in language. Space in Languages: Linguistic Systems and Cognitive Categories (Vol. 66) (pp. 59-81). doi:10.1075/ tsl.66.05slo 
Stein, N. L., \& Glenn, C. G. (1975). An analysis of story comprehension in elementary school children: A test of a schema. Retrieved from http://files. eric.ed.gov/fulltext/ED121474.pdf

Ventsov, A. V., Slepokurova, N. A., \& Snjuguina, E. A. (2011). Osobennosti pauzatsii spontannogo i pročitannogo tekstov [Specific features of pausing in reading and spontaneous speech]. In VInternational Workshop ,The Analysis of Russian Spontaneous Speech (AR3-2011) (pp. 27-32). Saint Petersburg: Sankt-Petersburgskij gosudarstvennyj universitet aerokosmičeskogo priborostrojenija.

Zwaan, R. A. (2016). Situation models, mental simulations, and abstract concepts in discourse comprehension. Psychonomic Bulletin \& Review, 23(4), 1028-1034. doi:10.3758/s13423-015-0864-x 